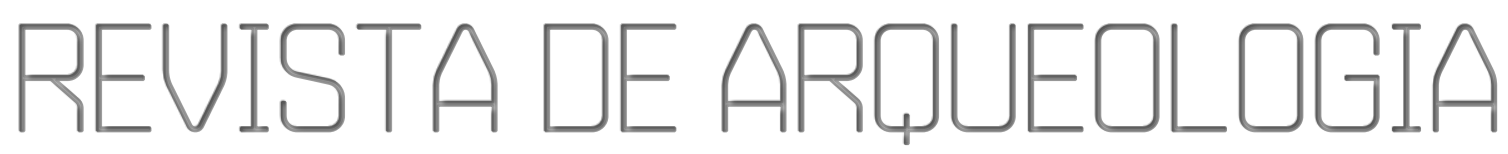

Volume 33 No. $3 \quad$ Setembro-Dezembro 2020

Edição Especial: Gestão de Acervos Arqueológicos

\title{
PERSPECTIVAS PARA A GESTÃO DE ACERVOS ARQUEOLÓGICOS
}

Daiane Pereira*, Diego Lemos Ribeiro**, Grasiela Tebaldi Toledo***, Silvia Cunha Lima****

A gestão dos acervos arqueológicos é indissociável do pensar e fazer arqueologia, museologia e conservação. As mudanças, permanências, avanços, retrocessos e desafios inerentes à salvaguarda e comunicação das coleções, nos distintos domínios institucionais, contam a própria história dessas disciplinas. As camadas mais recentes desse tema apontam para a necessária ampliação dos conceitos abordados pelas ciências direcionadas ao estudo do patrimônio e, no mesmo compasso, impulsionam o alargamento e profundidade das pesquisas, nomeadamente no que tange à gestão dos acervos e sítios arqueológicos.

A interface da arqueologia, museologia e conservação amplia o horizonte de temas que norteiam a gestão dos acervos arqueológicos. Profícuos debates transdisciplinares vêm sendo promovidos pelo Grupo de Trabalho Acervos da Sociedade de Arqueologia Brasileira (GTA-SAB), especialmente nas reuniões da $\mathrm{SAB}$ e nos Fóruns de Acervos, que já chegam a sua quarta edição, em coorganização com a Rede de Museus e Acervos Arqueológicos e Etnográficos (REMAAE).

O Grupo de Trabalho Acervos da Sociedade de Arqueologia Brasileira é um dos GTs que a SAB mantém para congregar associadas, associados e interessados em torno de temas candentes, com o objetivo de fomentar discussões que sejam traduzidas em ações concretas. O GTA-SAB, em particular, foi criado e formalmente registrado na Assembleia do XVIII Congresso da Associação, que ocorreu na cidade de Goiânia. Pode-se dizer que sua criação consubstanciou a militância de associadas e associados que, por décadas, impulsionaram a discussão sobre o tema da gestão de acervos dentro da SAB.

Transcorridos cinco anos desde sua consolidação, conseguiu-se reunir mais de 190 membros no Grupo, que mantêm-se coesos virtualmente e presencialmente. Eventos temáticos organizados pelo GTA passaram a ocorrer a partir de 2016, com destaque para o I Encontro de Ingresso de Acervos Arqueológicos em Instituições de Guarda, em Porto Alegre. O I Fórum Acervos

\footnotetext{
* Arqueóloga do Núcleo de Pesquisa Arqueológica (NuPArq) do Instituto de Pesquisas Científicas e Tecnológicas do Estado do Amapá (IEPA). E-mail: daianepereira.dp@gmail.com.

ORCID: http://orcid.org/0000-0002-7998-4836.

** Museólogo, Professor Adjunto do Curso de Bacharelado em Museologia e do Programa de PósGraduação em Memória Social e Patrimônio Cultural da Universidade Federal de Pelotas.

E-mail: dlrmuseologo@yahoo.com.br. ORCID: http://orcid.org/0000-0002-2433-4828.

*** Arqueóloga do Instituto do Patrimônio Histórico e Artístico Nacional (IPHAN).

E-mail: grasiela.toledo@gmail.com. ORCID: https://orcid.org/0000-0003-1085-2808.

**** Conservadora-restauradora autônoma. E-mail: silvia.cunhalima@gmail.com.
}

ORCID: https://orcid.org/0000-0003-0986-5054. 
Arqueológicos, contudo, ocorreu em 2017, na cidade de Ouro Preto. A partir deste momento, o evento ganhou os seus contornos atuais, coroando o desejo do grupo em criar um lugar de encontro e troca entre os membros do GTA-SAB e a REMAAE, anualmente. Nessa perspectiva, o coletivo tem buscado ampliar sua atuação, agregar novos atores, capilarizar as discussões e valorizar as especificidades regionais. Almeja-se com isso construções coletivas e interdisciplinares, sem perder de vista a diversidade de modelos institucionais.

O Dossiê Gestão de Acervos Arqueológicos traduz essa conjunção de esforços. De um lado, reflete uma proposta construída em coletivo, impulsionada por um grupo congruente de atores que militam em prol do patrimônio arqueológico; de outro, aponta para a heterogeneidade de perspectivas sobre a gestão de acervos, para as assimetrias entre teoria e prática e, logo, para as distintas formas de abordar o mesmo tema nos inúmeros contextos institucionais e regionais. Neste horizonte, o Dossiê reuniu contribuições sobre diferentes processos de gestão de acervos arqueológicos, com o objetivo de divulgar e ampliar os debates sobre essa linha de pesquisa e atuação, um dos principais pilares do GTA-SAB. Merece destaque o fato de a chamada pública de artigos para o Dossiê ter gerado notável ressonância. Os números surpreendem: foram mais de 50 autores envolvidos nos manuscritos enviados, em autoria e coautoria, e perto de 70 profissionais da área foram mobilizados para a realização de pareceres. O Dossiê, assim sendo, é o produto de um processo longo, consistente e multiprofissional.

Os artigos presentes no Dossiê evidenciam os processos de mudança do campo da gestão dos acervos arqueológicos no contexto brasileiro, abrindo profícuo espaço para refletirmos sobre o seu 'estado da arte'. Dentre essas mudanças, alguns pontos ficam evidentes, como o crescente interesse dos profissionais da arqueologia pela temática, assim como a ampliação de projetos e ações com ênfase na gestão das coleções arqueológicas. Esse cenário pulsante é reflexo de novas normativas legais em relação ao patrimônio arqueológico; da ampliação da divulgação de pesquisas nacionais e internacionais com esse enfoque, por parte de Instituições, órgãos fiscalizadores e pesquisadores; e de ações de fomento por parte de coletivos, como o GTA-SAB e a REMAAE.

Essa análise também deixa em evidência os desafios nacionais que precisam ser superados na área para sua consolidação como campo de pesquisa na arqueologia, museologia e conservação. Ainda são escassas as instituições que contam com profissionais e setores que desenvolvem pesquisas que tocam a gestão dos acervos arqueológicos, sendo, muitas vezes, algo que pesquisadores agregam às suas funções. O campo vive, ainda, um processo de maturação que denota fragilidades e descompasso com debates internacionais. Mesmo com muitos obstáculos, os textos demonstram o engajamento dos nossos colegas, somado aos avanços conquistados a partir de esforços individuais e coletivos.

Reunimos um grande número de trabalhos para este volume de maneira que fosse visível o cenário diverso e heterogêneo de perspectivas, percursos de pesquisas, desafios institucionais e as atuais reflexões teórico-metodológicas direcionadas à pesquisa na área de gestão de acervos arqueológicos. Em síntese, o Dossiê traduz a diversidade dos caminhos e caminhadas que aludem ao grande potencial da área. 
Para a abertura e encerramento deste Dossiê, temos a honra de apresentar os textos de duas convidadas. A Dra. Maria Cristina Oliveira Bruno, uma das grandes responsáveis pelo fomento e consolidação desta discussão em contexto brasileiro, abre o Dossiê com o artigo Acervos arqueológicos: relevâncias, problemas e desafios desde sempre e para sempre, no qual apresenta um panorama, caminhos percorridos e a percorrer no que se refere à gestão de acervos arqueológicos, destacando a longevidade dos acervos e como estes podem ser abordados por diferentes perspectivas, apontando que os desafios são para sempre. A Dra. Fernanda Bordin Tocchetto, fundamental articuladora para a criação e consolidação do Grupo de Trabalho Acervos, encerra o Dossiê com o artigo A formação da Coleção Arqueológica do Museu de Porto Alegre Joaquim Felizardo e as práticas de gestão implementadas, em que expõe a trajetória de formação da coleção arqueológica de um museu municipal até a gestão desse patrimônio, reforçando as responsabilidades institucionais com a conservação, extroversão e pesquisa sobre a cidade.

Outra colaboração fundamental para este Dossiê foi realizada pelos nossos parceiros da Rede de Museus e Acervos Arqueológicos e Etnográficos - REMAAE no artigo Resiliência do devir: notas sobre o lugar, o papel e a atuação da REMAAE na defesa das coleções arqueológicas e etnográficas brasileiras. Esse texto, feito a muitas mãos, presenteia-nos com um exercício de historicização analítica da atual e demais coordenações da REMAAE.

Os artigos Uma nova politica para um antigo acervo: a redescoberta das coleções arqueológicas do Museu Goeldi e A gestão das coleções arqueológicas no Museu Nacional, UFRJ: sobre caminhos pisados, desvios e continuidades inesperadas apresentam reflexões sobre duas instituições seculares que salvaguardam expressivas e históricas coleções arqueológicas. Em que pesem os desafios particulares, cada um desses estudos demonstra como essas coleções podem ser objeto de revisão no que tange às políticas de acervo e gestão do patrimônio arqueológico, projetando as instituições para o futuro. $\mathrm{O}$ artigo Presença/Ausência de museus na Amazônia Marajoara: entre desafios e perspectivas contemporânea, por sua vez, traz à baila reflexões sobre a ampliação do conceito de museu, abarcando diferentes espaços e lugares, configurando-se como potenciais espaços museais que oportunizam a gestão dos bens arqueológicos por diferentes atores. Assim, tanto instituições consolidadas, como suas ausências e/ou diferentes estruturas, consubstanciam as diferentes possibilidades da preservação patrimonial.

Nesta toada, entende-se que fazer museus ultrapassa a ideia de construir paredes, e que formar acervos é mais do que compor e "domesticar" objetos. Ao colocar essas ideias no horizonte, a gestão dos acervos arqueológicos se amplia substancialmente, aproximando-se das demandas e perspectivas contemporâneas. Nesse sentido, o artigo Para além dos objetos: experiências, narrativas e materialidades em processo de Musealização da Arqueologia e do Patrimônio Cultural Indígena nos brinda com conceitos e práticas que visam romper com a lógica colonialista e com as visões exóticas acerca dos povos nativos, compreendendo a musealização da arqueologia como um instrumento na luta antirracista. E o artigo Repensando as velhas práticas: transversalidade e os papéis da arqueologia e museologia na preservação do patrimônio do Parque Municipal 
Arqueológico Morro da Queimada - Ouro Preto, MG demonstra como a consolidação do campo da preservação do patrimônio cultural perpassa pela educação, envolvimento comunitário, interface entre arqueologia, museologia e conservação, além das perspectivas teóricas engajadas com as viradas ontológicas.

Os desafios da gestão dos acervos arqueológicos também intercruzam os necessários processos de pesquisa e implementação de políticas institucionais. Parte considerável das Instituições de Guarda e Pesquisa está criando ou adequando suas políticas de gerenciamento de coleções, alinhando-se às demandas atuais da disciplina arqueológica. A exemplo disso, destacam-se os artigos A política institucional da Universidade Federal do Maranhão para o gerenciamento e a salvaguarda dos acervos arqueológicos: uma história em três atos e $O$ papel dos endossos na musealização da arqueologia: interface público-privado no Museu de Arqueologia e Paleontologia de Araraquara (MAPA), que trazem reflexões e casos desse processo, analisando a formação dessas coleções, apresentando propostas e percursos de políticas institucionais. Integrando as reflexões sobre as políticas de gerenciamento de acervos, este Dossiê conta com dois textos que trazem um recorte a esse tema ao propor as bases para discutir o descarte no contexto das pesquisas arqueológicas. São eles: Aquisição e descarte de bens arqueológicos: a experiência de elaboração de uma Política de Acervos para o LASCA/UFSM e "Joga fora no lixo"? Reflexões sobre o descarte de espólio de pesquisas arqueológicas no Brasil.

É inequívoco que o patrimônio arqueológico musealizado vem passando por profundas transformações, não apenas no Brasil. Essas mudanças são motivadas pela força de dispositivos legais e/ou impulsionadas por um robusto movimento de mimetização dos museus de arqueologia e etnologia aos condicionalismos do contemporâneo. Esses deslocamentos geram efeitos que reverberam nas formas como os patrimônios são investigados, comunicados e mobilizados. O artigo Archaeological heritage management of the prehistoric art museum of Mação, Portugal coloca em debate o processo de reestruturação de um museu no contexto português. A partir de reminiscências do passado, a proposta de reformulação projeta no horizonte o futuro da gestão do patrimônio arqueológico na região, desde uma perspectiva integradora que enlaça comunidades locais, turistas e pesquisadores. O artigo Duas leis, um museu: o caso do National Museum of the American Indian, o Native American Graves Protection and Repatriation Acte o National Museum of the American Indian Act, no contexto norte-americano, discute como a legislação patrimonial tem o potencial de gerar processos museológicos consonantes com a agenda contemporânea do campo arqueológico. No mesmo compasso, e de modo retroalimentado, essas instituições também podem inspirar atualizações na legislação, nomeadamente no que concerne à repatriação de remanescentes humanos e objetos funerários.

A abertura de novos espaços que reiteram a integração entre comunidades locais e pesquisadores também desponta em território nacional com a criação e consolidação de instituições nas diferentes regiões. O engajamento na construção de diálogos plurissemânticos e a incorporação de uma diversidade de atores e coleções peculiares são os desafios e reflexões presentes no texto Pluralidade dos acervos epistêmicos na Amazônia: história, gestão e desafios do Laboratório de Arqueologia Curt Nimuendajú (UFOPA). Convergem com esse tema a dificuldade de se 
estabelecer parâmetros que dêem conta também da diversidade de biomas entre as regiões e a responsabilidade de propor estratégias de curadoria para coleções provenientes de contextos amazônicos e mantidas na região, questões que integram as discussões dos artigos Desafios e estratégias para a gestão de coleções de Remanescentes Humanos na Amazônia e Balaios de plantas e animais: conservação de macrovestígios orgânicos arqueológicos.

As coleções arqueológicas salvaguardadas lançam as bases para a criação de ações de diferentes dimensões, objetivando sua conservação e extroversão. $\mathrm{O}$ artigo NUVIS-UFPE: uma proposta inovadora de extroversão da reserva técnica associada ao laboratório LACOR-UFPE traz para o debate o papel que as reservas técnicas podem assumir como espaços de divulgação do acervo, potencializando o seu papel social. Os artigos Anotações sobre a documentação e a coleção Terena no MAE-USP (1914, 1947 e 1986) - Trajetória dos objetos e subsídios para pesquisas e A Coleção Von Koseritz: análise e curadoria científica de artefatos líticos polidos apontam para um novo olhar sobre as coleções, restabelecendo suas biografias por meio de estudos curatoriais que envolvam não apenas a revisão da documentação histórica, como também a proposta de ações que tramem nos objetos novos significados, funções e paradigmas. Com propósito análogo, o texto História de Vida de uma urna Marajoara: reconectando contextos e significados faz o exercício de compreender os deslocamentos semânticos de um objeto dentro da coleção, buscando agregá-lo em novas tramas de sentidos ao emaranhar coisas, sujeitos, tempos, conhecimentos e trajetórias, conectando as coleções com diferentes públicos.

Os acervos arqueológicos salvaguardados nos Museus e em Instituições de Guarda e Pesquisa, pelas diversas regiões do país, são importantes vetores relacionais entre pessoas e epistemes. Acervos que nos conectam com os passados indígenas, com os grupos colonizados, com as diferentes formas de domínio e resistência dos povos africanos e afro-brasileiros, e com os movimentos migratórios, conectando passado, presente e futuro dos diferentes grupos responsáveis pelos múltiplos processos de ocupação e manifestação que engendram a cultura material.

O engajamento com processos de gerenciamento de acervos arqueológicos que garantam a pesquisa, a conservação física e informacional, assim como sua extroversão e ressignificação, não é uma missão puramente cartorial, mas sobretudo um compromisso social e humano, atento às tensões entre memória $\mathrm{e}$ esquecimento, entre silenciamentos e visibilidades, entre valorização e abandono. Acreditamos que as ações e as pesquisas reunidas neste Dossiê são perspectivas para esse caminho, mostrando que a gestão dos acervos arqueológicos exerce um papel fundamental como parte da pesquisa para a construção da história de longa duração.

Almejamos que a leitura do Dossiê seja tão prazerosa e recompensadora como foi para nós participarmos de sua organização. Boa leitura!

AGRADECIMENTOS

À Comissão Editorial da Revista de Arqueologia, Fernanda Codevilla Soares, Luís Cláudio Pereira Symanski e Rafael Milheira, por ter aceito a proposta deste 
número temático e pela assistência e esmero ao longo dos últimos meses. Às autoras e autores das quase quarenta contribuições que foram submetidas, que nos encheram de otimismo para um campo da gestão de acervos arqueológicos mais múltiplo e fortalecido. Aos profissionais que generosamente aceitaram compartilhar suas reflexões e leituras críticas através de pareceres anônimos. 